\title{
Bruno, Paula, Martín García Mérou. Vida intelectual y diplomática en las Américas, Bernal Universidad Nacional de Quilmes Editorial, 2018, 216 pp. ISBN: 978-987-558-534-8
}

El nuevo libro de Paula Bruno representa su segunda colaboración como autora en la colección “La ideología argentina y latinoamericana”, en un inicio a cargo de Oscar Terán y actualmente dirigida por Jorge Myers. Su título precedente en dicha colección es Travesías intelectuales de Paul Groussac (2004). Destacamos que Bruno ha publicado otros libros y numerosos artículos sobre la vida intelectual argentina, por lo que constituye una voz consolidada en el campo de la historia de los intelectuales y resulta por ello un referente importante en el ámbito historiográfico argentino e internacional.

En esta ocasión Bruno nos ofrece un trabajo de investigación de admirable exhaustividad en torno a la figura de Martín García Mérou (1862-1905), el cual puede considerarse al mismo tiempo un valioso estudio sobre la relación entre el mundo diplomático e intelectual latinoamericano en el cambio de siglo. El volumen está presidido por un ensayo de 50 páginas donde la autora despliega una semblanza completa de esta figura, expone sus ideas sobre la recepción de su obra y problematiza los estudios existentes dedicados tanto a esta personalidad como a las caracterizaciones más comunes referidas a la figura del intelectual en el cambio de siglo y las perspectivas de los estudios sobre diplomacia. Para ello, Bruno consultó no sólo la obra editada del autor en sus múltiples géneros — ensayos, memorias, notas de coyuntura, relaciones de viajes y recuerdos de estadías, sus poemarios y su única novela-, sino también exhumó con sistematicidad materiales inéditos

* Universidad Nacional de General San Martín/ConicEt, Buenos Aires, Argentina. Correo electrónico: pabloortemberg@gmail.com 
del Fondo Martín García Mérou, del Instituto Bibliográfico “Antonio Zinny”; del Fondo Documental del Museo Roca y los legajos del Archivo Histórico de la Cancillería Argentina. El resto del libro reproduce capítulos o fragmentos de textos editados de García Mérou, los cuales, con excepción de Recuerdos Literarios (1891), no habían sido reeditados y algunos circulaban dispersos en diferentes formatos. El criterio de selección obedeció a los ejes temáticos abordados en el ensayo introductorio, organizado en cuatro secciones: "Trayectorias y recuperaciones", "Cartografías y constelaciones latinoamericanas", "Vida intelectual argentina” y "Conocer y escribir las Américas".

Si en uno de sus libros precedentes, Pioneros culturales de la Argentina. Biografías de una época (Siglo Veintiuno Eds., 2011), la autora analizó la sociabilidad intelectual en el espacio nacional, y luego, como coordinadora de Visitas culturales en la Argentina, 1898-1936 (Biblos, 2014), se interesó en la dimensión internacional de la vida cultural, esta obra dedicada al intelectual-diplomático García Mérou le permitió a Bruno conjugar en un solo itinerario biográfico lo nacional y lo internacional, una apuesta que la condujo necesariamente a abrir su campo de interés hacia la historia diplomática. Así, la obra se inscribe en una renovada agenda de investigación compartida por colegas que, en los últimos años, estamos volviendo la mirada sobre la historia diplomática desde coordenadas culturales.

En este sentido, este libro arroja luz sobre los modos en que se combinaron las actividades de intelectual y diplomático en Martín García Mérou, desde que el joven poeta iniciara a los 19 años su derrotero en la diplomacia formal, como secretario ad honorem de Miguel Cané en la misión a Colombia y Venezuela, hasta su muerte prematura a los 42 años, cuando acababa de ser nombrado ministro en Berlín. Los diplomáticos de entonces eran figuras multifacéticas en una época donde los "pioneros culturales" —para retomar la imagen acuñada por Bruno- ejercían sus funciones cuando las esferas de profesionalización e institucionalización se encontraban todavía en ciernes. Los trabajos precedentes consagrados a la figura de García Mérou hicieron hincapié en el poeta, o bien en el crítico literario, y algunos pocos se detuvieron, separadamente, en su rol de diplomático. La ponderación en detalle de cada uno de estos aspectos del semblante de García Mérou es el primer gran aporte a destacar del libro de Bruno.

Uno de los valores centrales que hace relevante el análisis integral de la vida y obra de esta figura, tal como señala la autora en su ensayo, es que García Mérou fue el primero en cartografiar la sociabilidad intelectual de espacios americanos que en su época se conocían superficialmente. Desde 1886, investigó y estudió con sistematicidad la realidad de los lugares en los que residió ejerciendo funciones en diversas legaciones como ministro, secretario o delegado: Venezuela y Colombia, Paraguay (en la selección es 
impresionante el testimonio que deja sobre los últimos días de Domingo F. Sarmiento en Paraguay), Brasil, pero también ciudades de Estados Unidos (la selección de textos nos muestra un conocimiento profundo de este país en todas sus dimensiones: social, económica, política y cultural), y capitales europeas como Madrid, París y —aunque estuvo allí muy poco tiempoBerlín. Así, Bruno prueba con consistencia en qué medida García Mérou "tomó distancia de los abordajes impresionistas y ensayó, frente a ellos, esfuerzos interpretativos basados en el estudio sistemático de la literatura, la historia y la geografía de otras naciones y en información jurídica, legal y diplomática obtenida en las legaciones (...) Aquello, concluye, "lo distancia de los climas corales". ${ }^{1}$

En efecto, la selección de textos constituye una fina curaduría realizada con inteligencia. Por ejemplo, nos permite reconocer en sus escritos el paso del pintoresquismo usual de los gentlemen viajeros al estudio en profundidad del mundo intelectual local, contraste que queda patente en el caso de Brasil. El primer fragmento de la selección "De paso por Río de Janeiro. En París", de 1884, comienza con la descripción de la llegada por mar a la Bahía de Río de Janeiro. García Mérou anota: "nos rodeaba un círculo de montañas verdes, graciosas, teniendo a un lado el majestuoso Pan de Azúcar que se incorporaba entre las brumas como un gladiador que acaba de derribar a su adversario (....) sobre las montañas se escalonaban las habitaciones blancas y audaces como las cabras salvajes"; destaca "las faldas cubiertas de vegetación”, y todo el conjunto lo deja "estático y maravillado". ${ }^{2}$ Como advierte Bruno, los viajeros que pasaban por Río de Janeiro en la segunda mitad del siglo XIX solían repetir, en sus impresiones, los tópicos esbozados por Domingo F. Sarmiento en su conocido viaje al Brasil. Más tarde, en el fragmento del libro El Brasil intelectual, de 1900, nos sorprende el cambio de registro. Aparece ahora el análisis crítico de un caudal de escritores de diferentes regiones del Brasil, los vínculos entre ellos, y hasta da cuenta con detalle de cómo funcionan la prensa y las redacciones en el país vecino, siempre en espejo con la realidad argentina y otras partes del mundo. Si en el Corán no hay camellos, como recordaba J. L. Borges, en El Brasil intelectual del residente García Mérou ya no hay frutas tropicales ni vegetación exuberante.

Si se me permite una digresión, ese apartado sobre Brasil me incitó a pensar en la dificultad de eludir el pintoresquismo en los relatos de viajes de ayer y de hoy. No obstante, la calidad de la pluma y el poder de observación de detalles inusitados pueden redimir el lugar común. Incluso, haciendo una

Bruno, Martín García Mérou. Vida intelectual y diplomática en las Américas, p. 55.

Ibíd., p. 63. 
extrapolación, cuando la primera frase "anti-pintoresquista" o "anti-exotista" del Tristes Trópicos de Claude Lévi-Strauss, obra de mediados del siglo XX, es "odio los viajes y los exploradores", el capítulo 9 intitulado "Guanabara”, al igual que en ese fragmento juvenil de García Mérou, transmite su impresión "maravillada" al arribar a Río de Janeiro por agua (un arribo medio siglo posterior al otro). Sin embargo, el pintoresquismo o el lugar común se sacude en la pluma de Lévi-Strauss desde la primera frase de ese capítulo: "Río de Janeiro es mordida por su bahía hasta el corazón; se desembarca en pleno centro, como si la otra mitad, nueva Ys, ya hubiera sido devorada por las olas". Tan bella como pintoresca esa imagen del etnólogo francés nos enseña que el lugar común puede ser tratado de modo original, valga el oxímoron. Por lo tanto, volviendo a García Mérou, en aquel primer fragmento de impresiones de viaje, su observación y su pluma no dejan de dignificar, a mi parecer, los lugares comunes. Aún más, en su paseo de "turista"-flâneur (otro oxímoron) por París busca identificar lugares comunes de la literatura, pues nos advierte que "París se estudia como un libro". Así, llega a escribir pasajes como "el parque silencioso y poético de Monceaux nos habla de los desórdenes de la Comuna, nos recuerda las mujeres fusiladas en su seno; las Buttes Chaumont aún guardan en su cumbre más alta las sombras de los ahorcados en Montfaucon, todas las orgías de la barbarie ensañándose en la masa humilde de los oprimidos; en la Plaza de la Concordia buscamos las manchas de la sangre de María Antonieta; la columna de Julio nos habla de los héroes de 1830; en todas partes hay un hecho que se levanta del pasado, una voz que nos conmueve, un recuerdo que nos despierta". ${ }^{3}$ En fin, son muchos los pasajes de un García Mérou viajero donde el lugar común se transfigura gracias a una pluma singular, y vale la pena detenerse en esa mirada.

Bruno también analiza los posibles motivos por los cuales en El Brasil intelectual, García Mérou juzga a este país, en el que reside como ministro, superior a la Argentina en cuanto a modernización cultural y científica. El intelectual-diplomático está fascinado por sus instituciones culturales bajo patrocinio del imperio, continuadas durante la república, a la vez que se lamenta - el lamento es una forma de intervención del intelectual en la época, tal cual señaló Terán y también nos recuerda Bruno- por el poco apoyo financiero al mundo intelectual por parte del gobierno argentino. $\mathrm{Al}$ mismo tiempo, la autora encuentra en diversos documentos una sensación de incomodidad en García Mérou puesto que en aquellos momentos en que proyectaba escribir su libro se estaba dirimiendo ríspidamente entre los dos 
países la cuestión Misiones-Palmas. En este sentido, el libro El Brasil intelectual sirvió luego de ofrenda de confraternidad en el marco de la política de acercamiento entre Brasil y Argentina, cuando en 1899 y 1900 se concretaron las sendas visitas de los presidentes Julio A. Roca y Manuel Ferraz de Campos Salles. Esto nos ilustra sobre las singulares combinaciones que podían suscitarse entre el proyecto creador de un intelectual de la época y los mecanismos de la diplomacia en la coyuntura regional.

Asimismo, García Mérou consideraba que Brasil estaba mejor posicionado que Argentina en el espacio geopolítico y juzgaba fundamental su aproximación sin titubeos con la nueva gran potencia que se vislumbraba en el norte, un acercamiento que estaban lejos de emular los sectores influyentes de la élite argentina. En el plano geopolítico, Bruno escogió para su selección dos textos de García Mérou sobre acontecimientos significativos que contribuyeron a modificar las representaciones sobre las Américas. Uno de ellos es su examen sobre la Primera Conferencia Panamericana de 1889, donde expresa un juicio auspicioso respecto del proyecto panamericanista. Mientras el texto se muestra elogioso por la labor de los delegados argentinos en ese escenario, Bruno encuentra que, en la correspondencia privada dirigida a Julio A. Roca, el diplomático los acusa de haber realizado una deplorable actuación. Del mismo modo, en notas privadas critica al ministro que le precedió en la Legación argentina en Brasil, según él, escandalosamente despreciativo, en términos racistas, con la población local; es decir, lo opuesto a lo que se esperaría del arte diplomático. En artículos anteriores (véase, por ejemplo, "Martín García Mérou y su vida diplomática en Estados Unidos, 1896-1900 y 1901-1905”, publicado por la autora este año en el número 156 de esta revista, pp. 143-180), Bruno abordó la cuestión diplomática y la circulación de informes apoyada esencialmente en este tipo de documentación que, en el ensayo, escogió utilizar sólo en momentos clave en función de la restitución integral de este personaje multifacético. El último texto de la selección refiere a la guerra hispano-norteamericana por Cuba en 1898, un punto de inflexión de la corriente hispanoamericanista. Al calor del conflicto, el intelectual-diplomático García Mérou se convirtió también en moderno corresponsal de guerra contratado por el periódico La Nación. Desde suelo norteamericano envió notas, firmadas con seudónimo, con valoraciones oscilantes respecto a la sociedad norteamericana. De este modo, el argentino fue en esta coyuntura una pieza importante en la historia de la modernización del periodismo, regido cada vez más por los imperativos de la velocidad de la circulación de las noticias a escala global.

Los estudios encarados por García Mérou también redundaron en dos obras historiográficas de consideración: Historia de la diplomacia americana (1904) e Historia de la República Argentina (1899), esta última para uso en las escuelas. Como examina Bruno, también contempló un proyecto de 
historia del pensamiento argentino, con ensayos sobre Juan B. Alberdi, Esteban Echeverría y otras personalidades paradigmáticas. Subraya la autora que pese a la variedad de registros y temas que abordó, la posteridad sólo retuvo de él su ensayo crítico Recuerdos Literarios (1891), donde retrata la vida cultural de Buenos Aires de 1870. Incluso aquí Bruno critica el habitual uso simplificador que se ha hecho de esta obra. Se la suele utilizar para dar cuenta de la vida cultural de un genérico cambio de siglo. Lejos de ser una única fotografía, aquellos años se han caracterizado, tal como la autora argumenta con solvencia en numerosos trabajos, por constantes y dinámicas reconfiguraciones. Así, Bruno nos recuerda que a García Mérou se le ha catalogado como “mero cronista de la 'generación del 80’”. ${ }^{4}$ Es interesante la discusión entonces que entabla la analista con ciertas lecturas de la obra de esta personalidad. Algunos lo vieron como copia lavada de Miguel Cané, especialmente David Viñas, quien parece enojado también por su admiración hacia Estados Unidos y se muestra corrosivo respecto de la actividad diplomática del "gentleman-escritor". En todo caso, la crítica literaria en general se ha detenido casi exclusivamente en el García Mérou crítico. Únicamente el trabajo de 1965 de Nicolás Cócaro ha abordado a este personaje de manera integral. El ensayo de la compiladora, en este sentido, desarrolla un necesario análisis integral y menos segmentado de este personaje a partir de las cuatro secciones mencionadas más arriba y que tienen en consideración sus escritos sobre la vida cultural latinoamericana, aquellos referidos a la vida cultural argentina y sus apreciaciones sobre la geopolítica americana.

Para concluir, el ensayo de Bruno ausculta con especial agudeza los diferentes momentos a los que refieren las distintas publicaciones de García Mérou sobre la vida cultural argentina. En su análisis, la autora evidencia las cambiantes constelaciones del entramado intelectual, reflejadas en las también cambiantes percepciones que trasuntan los textos críticos de García Mérou sobre este universo en diferentes años. Todo ello nos hace ver una lúcida apuesta historiográfica por parte de la autora, otro de los aciertos a destacar de este libro. Al terminar su análisis nos queda claro que el período abordado erróneamente podría considerarse un todo homogéneo o reducirse con pocos parámetros bajo la rúbrica "cambio de siglo", o quedar cristalizado en cómodas etiquetas como "positivismo" o "Generación del '80". Es ya un sello historiográfico de la autora eludir tanto las simplificaciones como las interpretaciones ancladas en un registro mecánico que definen al intelectual según su clase social, o según un tipo de vínculo específico establecido con un Estado considerado como monolítico. Sobre esto último, Bruno se 
distancia también de los enfoques tradicionales de la historia diplomática que parten del supuesto de la existencia de un Estado poseedor de una política exterior delimitada, donde los diplomáticos serían meros ejecutores. Lejos de ello, en este nuevo libro, Paula Bruno demuestra una vez más la complejidad de un mundo intelectual en ebullición y da muestra de la heterogeneidad cambiante de los espacios de sociabilidad intelectual, las representaciones diversas sobre la cuestión nacional y la geopolítica, así como también reconstruye los perfiles posibles de la labor diplomática, un área crucial en vías de profesionalización en aquella época. Por todo esto, estamos ante un valioso aporte para entender mejor la variedad de modos en que los intelectuales se vincularon con el poder político, contribuyeron en el diseño de instituciones estatales y establecieron puentes culturales más allá de las órbitas nacionales. 